\title{
Impact and Fracture Resistance of an Experimental Acrylic Polymer with Elastomer in Different Proportions
}

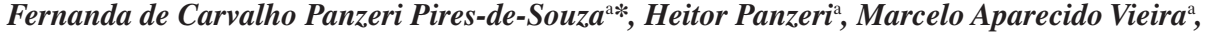 \\ Lucas da Fonseca Roberti Garcia ${ }^{\mathrm{b}}$, Simonides Consani ${ }^{\mathrm{b}}$ \\ a'Department of Dental Materials and Prosthodontics, Ribeirao Preto School of Dentistry, \\ University of Sao Paulo - USP, \\ Av. do Café, s/n, Monte Alegre, 14040-904 Ribeirão Preto - SP, Brazil \\ ${ }^{\mathrm{b}}$ Department of Restorative Dentistry, Dental Materials Area, Piracicaba School of Dentistry, \\ State University of Campinas - UNICAMP, Piracicaba - SP, Brazil
}

Received: March 24, 2009; Revised: October 21, 2009

\begin{abstract}
The purpose of this study was to evaluate the impact and fracture resistance of acrylic resins: a heat-polymerized resin, a high-impact resin and an experimental polymethyl methacrylate with elastomer in different proportions (10, 20, 40 and 60\%). 120 specimens were fabricated and submitted to conventional heat-polymerization. For impact test, a Charpy-type impact tester was used. Fracture resistance was assessed with a 3-point bending test by using a mechanical testing machine. Ten specimens were used for each test. Fracture (MPa) and impact resistance values $\left(\mathrm{J}^{\mathrm{m}} \mathrm{m}^{-1}\right)$ were submitted to ANOVA - Bonferroni's test - 5\% significance level. Materials with higher amount of elastomer had statistically significant differences regarding to impact resistance $(\mathrm{p}<0.05)$. Fracture resistance was superior $(\mathrm{p}<0.01)$ for high-resistance acrylic resin. The increase in elastomer concentration added to polymethyl methacrylate raised the impact resistance and decreased the fracture resistance. Processing the material by injection decreased its resistance to impact and fracture.
\end{abstract}

Keywords: impact testing, fracture toughness, poly (methyl methacrylate), elastomer

\section{Introduction}

Polymethyl methacrylate (PMMA) has been used in dental prosthetic devices for almost 70 years. Three fundamental features have contributed for its success: excellent appearance, simple processing technique and easiness of the repair. However, the resistance to impact and fracture of PMMA during function are low $^{1}$.

Several studies have investigated the incidence and type of fractures in prosthetic devices and observed that midline fractures of denture base are common ${ }^{2-5}$. These failures are related to the development of microscopic fissures in areas of stress concentration, forming cracks that weaken the material. Stress lines are normally caused by a high impact outside of the mouth as accidental drops of removable prostheses.

Advances in polymer science allow the introduction of new processing and activation techniques, such as injection molding, chemical modification of PMMA by adding rubber-based polymers and reinforcing PMMA with carbon, polyethylene fibers and fiberglass. These improvements have been overcoming the material limitations and favoring the mechanical properties ${ }^{6-10}$. Dispersion of rubber-based composite particles within the PMMA matrix allows that tension generated by impact propagate though the material, losing acceleration and improving in the rubber/PMMA interface. Therefore, the material can absorb the energy generated by impacts, avoiding fractures and allowing that the prosthetic device function adequately for longer periods ${ }^{11,12}$. The fracture resistance of highimpact PMMA was twice than those of the conventional resins ${ }^{13}$. Cross-linked agents as ethylene glycol dimethacrylate were also suggested to be incorporated to PMMA in order to properly plastify the material and enhance the mechanical properties ${ }^{14-17}$.
The main scope of the present study was to compare in vitro the resistance to impact and fracture of usual heat-polymerized resin, high-impact acrylic resin and an experimental PMMA-based acrylic resin, with addition of 10, 20, 40 and 60\% acrylic elastomer, processed using conventional or injection technique. The tested hypothesis is that the elastomer added to PMMA will produce a more resistant material to impact and fracture than the conventional materials. Besides, it is supposed that higher percentages of elastomer added to PMMA will produce materials more resistance to impact and fracture.

\section{Materials and Methods}

\subsection{Specimen fabrication}

Specimens made of polymers (available on the market and experimentals) were submitted to resistance tests to impact and fracture. Three materials were used in this study: heat-polymerized acrylic resin (Clássico, Clássico Produtos Odontológicos, São Paulo, SP, Brazil), high-resistance heat-polymerized acrylic resin (Lucitone550, Dentsply/Caulk, Rio de Janeiro, RJ, Brazil) and PMMA with addition of $10 \%$ (EDA), $20 \%$ (EDB), 40\% (EDC), and 60\% (EDD) elastomer (Companhia Química Metacril $^{\circledR}$, São Paulo, SP, Brazil). Ten specimens were prepared from each material for fracture toughness and impact tests. These specimens were made using a standard Teflon matrix $(65 \times 10 \times 4 \mathrm{~mm})$ invested in flasks with type IV dental stone (Durone; Dentsply/Caulk, Rio de Janeiro, RJ, Brazil) and clamped (Hydraulic Clamp, VH Soft Line, VH Dental Equipments, Araraquara, 
SP, Brazil) for 30 minutes at $1200 \mathrm{psi}$, then polymerized under water bath in a cycle of 90 minutes at $73{ }^{\circ} \mathrm{C}$ and 30 minutes at $100{ }^{\circ} \mathrm{C}$.

The experimental materials are presented as granules (Figure 1) and were transformed into a pliable mass when submitted to heat. According to the manufacturer, this material should be molded by the injection technique. Therefore, in order to obtain specimens from this material, a metallic mold with four chambers for plastic injection was made. This mold had the same dimensions of the Teflon ${ }^{\circledR}$ matrix.

In the beginning, the material was heated (Odontobrás Dry Heat Sterilizer, Ribeirão Preto, SP, Brazil) at $110^{\circ} \mathrm{C}$ for 4 hours. Afterwards, it was heated at $235^{\circ} \mathrm{C}$ and injected into the mold using an injection device (Himaco LHS 400, Icarplast, Ribeirão Preto, SP, Brazil) under a pression of 70 Bar. Another manner of transforming this material into a pliable mass is dissolving the polymer into the monomer. For this procedure, the material was pulverized using a polymer grinder (Micron Powder System CS BANTAM - 98000860, Summit, NJ, USA) and an initiator $(0.2 \%$ benzoyl peroxide). The polymer was mixed with its monomer and manipulated following the usual technique for polymerization of denture bases. After the cycle was completed, the specimens were removed from the flask, manually buffed and polished using sandpaper with \#300, 500, 800, and 1000 granulation. The specimens' dimensions were standardized at $0.1-\mathrm{mm}$ precision (Pocket Thickness Gage, Mitutoyo, Kawasaki, Japan).

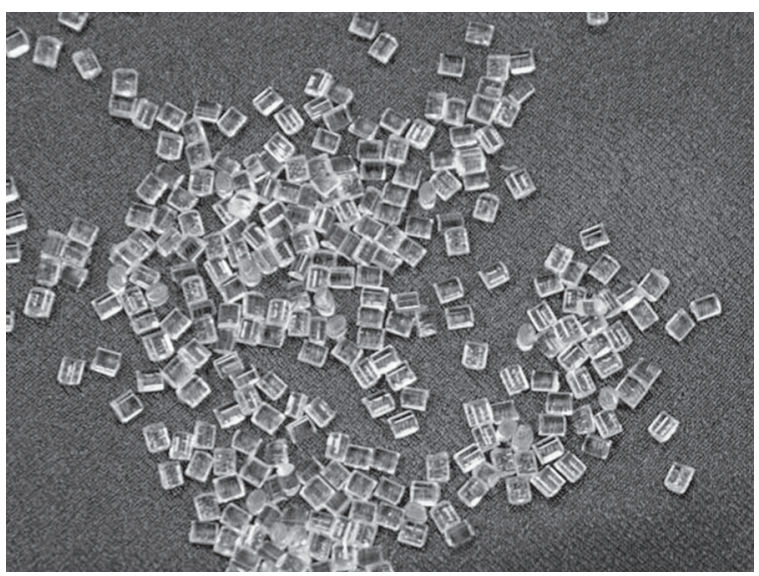

Figure 1. Experimental material (ED).

\subsection{Impact and fracture tests}

After polishing, the specimens were stored in distilled water at $37{ }^{\circ} \mathrm{C}$ for 28 days before testing in order to simulate oral conditions. Resistance to impact was evaluated by Charpy test (Impact Device CEAST - model Resil 25 - CCSi, Akron, OH, USA) with a load of $4 \mathrm{~J}$. Factors as friction of the pendulum against the air, rupture force and thickness of the specimen were considered when calculating impact resistance. These variables were included in the equation: $\mathrm{Ri}=(\mathrm{Fa} / \mathrm{e}) \times 1000$, where $\mathrm{Ri}=$ impact resistance, $\mathrm{F}=$ maximum force, $\mathrm{a}=$ Friction and $\mathrm{e}=$ thickness. Fracture resistance test (Universal Test Device EMIC-MEM 2000, São José dos Pinhais, PR, Brazil) was performed with $50 \mathrm{Kgf}$ load and a cross-speed of $5 \mathrm{~mm} / \mathrm{min}$ until complete failure. Rupture values were used to calculate resistance to fracture by means of the equation:

$$
\mathrm{F}_{\mathrm{s}}=\left(3 \mathrm{P}_{\mathrm{m}} 1 / 2 b h^{2}\right)
$$

where $\mathrm{F}_{\mathrm{s}}=$ fracture resistance, $\mathrm{P}_{\mathrm{m}}=$ maximum load, $1=$ distance between props under the specimens, $\mathrm{b}=$ width of the specimen, $\mathrm{h}=$ thickness. Values obtained were submitted to statistical analysis using ANOVA and Bonferroni's test at 5\% significance level.

\section{Results}

Regarding the resistance to impact, when the ground materials were compared to the controls (Table 1), it was verified that the materials with higher elastomer percentages (EDC and EDD) had superior resistance values, statistically different from the commercial resins $(\mathrm{p}<0.001)$. The resins with smaller percentage of elastomer (EDA and EDB) presented inferior mean values than the commercial resins, statistically different from the Lucitone 550 resin $(\mathrm{p}<0.01)$. Regarding the injected materials (Table 2), the highest resistance was found for EDC, with mean values statistically different from the commercial materials $(\mathrm{p}<0.05)$. The EDA and EDB resins also showed the smallest resistance values, also statistically different from the commercial materials $(\mathrm{p}<0.001)$. The EDD resin was the only material that had similar performance to the commercial materials, with results without significant statistical difference between the commercial materials $(\mathrm{p}>0.05)$.

Comparing the results of the experimental materials regarding the processing technique (Figure 2), it was verified that, overall, the ground materials had higher resistance values to impact than the in-

Table 1. Impact resistance $\left(\mathrm{J} \cdot \mathrm{m}^{-1}\right)$. Comparison of commercial materials and ground experimental materials (1-way ANOVA and Bonferroni's test $\mathrm{p}<0.05)$

\begin{tabular}{|c|c|c|c|c|c|}
\hline & & EDA & EDB & EDC & EDD \\
\hline & & $123.0( \pm 11.0)$ & $125.5( \pm 5.70)$ & $219.3( \pm 5.36)$ & $227.3( \pm 7.81)$ \\
\hline Lucitone & $163.1( \pm 2.88)$ & $\mathrm{p}<0.01$ & $\mathrm{p}<0.01$ & $\mathrm{p}<0.001$ & $\mathrm{p}<0.001$ \\
\hline Clássico & $143.6( \pm 4.48)$ & NS & NS & $\mathrm{p}<0.001$ & $\mathrm{p}<0.001$ \\
\hline
\end{tabular}

NS = Non-significant.

Table 2. Impact resistance $\left(\mathrm{J} . \mathrm{m}^{-1}\right)$. Comparison of commercial materials and injected experimental materials (1-way ANOVA and Bonferroni's test $\mathrm{p}<0.05)$.

\begin{tabular}{cccccc}
\hline & & EDA & EDB & EDC & EDD \\
\hline & & $88.6( \pm 6.70)$ & $107.6( \pm 8.17)$ & $195.3( \pm 9.91)$ & $162.7( \pm 9.54)$ \\
Lucitone & $163.1( \pm 2.88)$ & $\mathrm{p}<0.001$ & $\mathrm{p}<0.001$ & $\mathrm{p}<0.05$ & $\mathrm{NS}$ \\
Clássico & $143.6( \pm 4.48)$ & $\mathrm{p}<0.001$ & $\mathrm{p}<0.05$ & $\mathrm{p}<0.001$ & $\mathrm{NS}$ \\
\hline
\end{tabular}

NS = Non-significant. 
jected materials (both with the same concentration of elastomer), and were statistically different from EDA $(\mathrm{p}<0.05)$ and EDD $(\mathrm{p}<0.001)$ (smaller and larger elastomer percentage respectively). When comparing the resistance to impact considering the amount of added elastomer (Figure 2), it was observed for the ground specimens that the resistance to impact increased with higher elastomer concentrations. When the specimens were injected, the EDC material had the highest resistance values to impact, followed by the EDD, statistically different from the other materials $(\mathrm{p}<0.05)$. The EDA and EDB had similar performance amongst themselves, without significant statistical difference between both materials ( $p>0.05)$.

Regarding the resistance to fracture and comparing the ground materials to the commercials (Table 3), it was verified that the EDC had the highest resistance mean values, however, these values were only statistically different from the Classic material $(\mathrm{p}<0.001)$. The Lucitone 550 was statistically different from EDA $(\mathrm{p}<0.001)$, which exhibited the inferior means. Regarding the injected material (Table 4), the Lucitone 550 had the higher values, statistically different from the experimental materials $(\mathrm{p}<0.001)$. The heat-polymerized Classico resin had similar resistance values than those recorded by the experimental materials, and both were statistically different from EDB $(p<0.05)$, which showed the lowest strength values.

The comparative analysis of the experimental materials with the same concentration of elastomer according to the processing technique (Figure 3) revealed that, except the EDA, the ground materials had better results than the injected ones, with significant statistical difference from the EDB $(p<0.01)$, EDC $(p<0.001)$

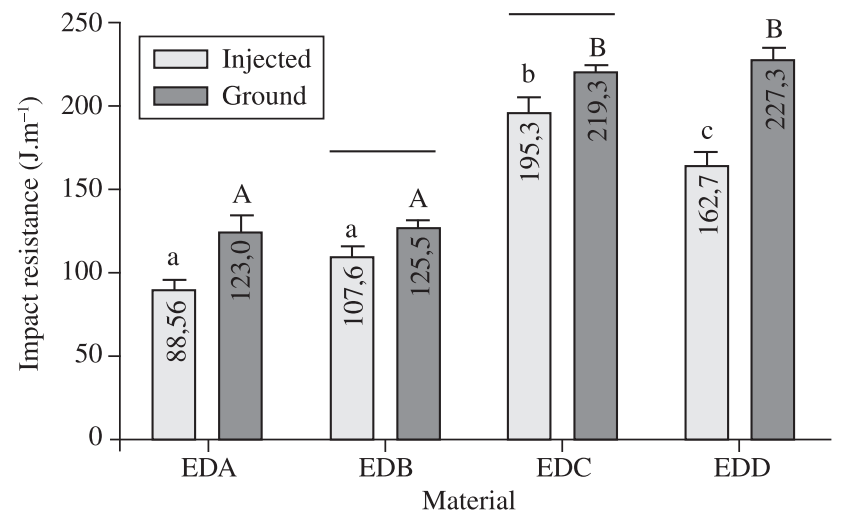

Figure 2. Impact resistance. Comparison (2-way ANOVA - Bonferroni $\mathrm{p}<0.05$ ) of commercial and experimental materials (ground and injected). and EDD ( $p<0.001)$ materials. For the EDA, the injected form revealed superior mean values, similar from the ground materials $(p>0.05)$. Comparison among the ground materials disclosed that the only specimen that presents significant statistical difference was EDA $(\mathrm{p}<0.05)$. The remaining materials had similar performance $(\mathrm{p}>0.05)$. No statistical differences were observed among the injected materials $(\mathrm{p}>0.05)$.

\section{Discussion}

Denture fractures are derived from large transitory forces caused by an accident or a small strength during repeated chewing. Tensions transferred to the prosthesis may vary according to the age of the patient, chewing force, nutritional habits and degree of awareness regarding the utilization of the prosthetic device. Flexural and impact tests have been used to examine these forces ${ }^{1,5}$.

In the present study, the tested hypothesis can be partially confirmed. According to the obtained results, the experimental materials with higher percentages of elastomer had better resistance to impact than the commercial ones. Nevertheless, with the addition of elastomer in smaller proportions (10 and 20\%), the improvement was not evident.

The elastomer added to the PMMA acted as a plastifying agent. Plastifying agents are frequently incorporated to the resin matrix to reduce its glass transition temperature and reduce the module of

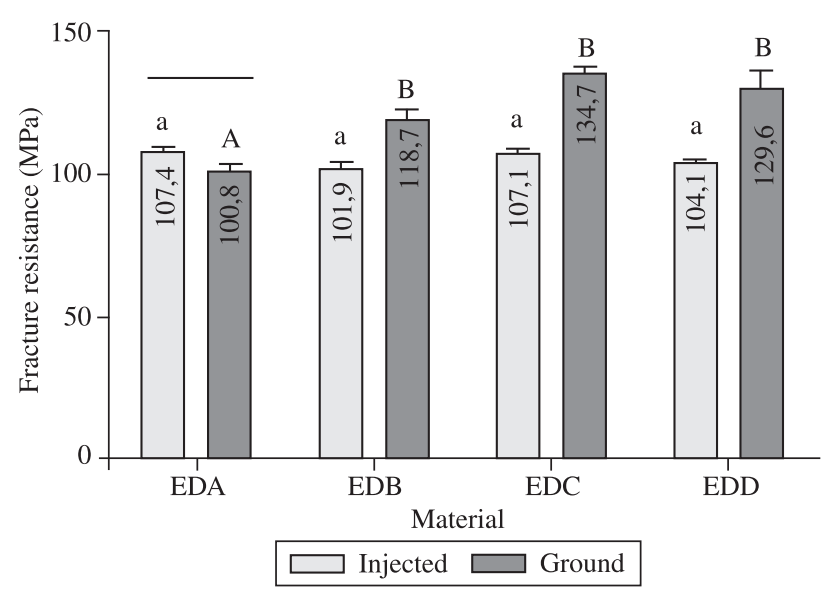

Figure 3. Fracture resistance. Comparison (2-way ANOVA - Bonferroni $\mathrm{p}<0.05$ ) of commercial and experimental materials (ground and injected).

Table 3. Fracture resistance (MPa). Comparison of commercial materials and ground experimental materials (1-way ANOVA and Bonferroni's test $\mathrm{p}<0.05$ ).

\begin{tabular}{cccccc}
\hline & & EDA & EDB & EDC & EDD \\
\hline & & $100.8( \pm 2.82)$ & $118.7( \pm 3.94)$ & $134.7( \pm 3.12)$ & $129.6( \pm 6.96)$ \\
Lucitone & $132.8( \pm 1.04)$ & $\mathrm{p}<0.001$ & $\mathrm{NS}$ & $\mathrm{NS}$ & $\mathrm{NS}$ \\
Clássico & $109.9( \pm 2.37)$ & $\mathrm{NS}$ & $\mathrm{NS}$ & $\mathrm{p}<0.001$ & $\mathrm{p}<0.01$ \\
\hline
\end{tabular}

NS = Non-significant.

Table 4. Fracture resistance (MPa). Comparison of materials available in the dental market and injected experimental materials.

\begin{tabular}{lccccc}
\hline & & EDA & EDC & EDD \\
\hline & & $107.4( \pm 2.19)$ & $101.9( \pm 2.39)$ & $107.1( \pm 1.91)$ & $104.1( \pm 0.79)$ \\
Lucitone & $132.8( \pm 1.04)$ & $\mathrm{p}<0.001$ & $\mathrm{p}<0.001$ & $\mathrm{p}<0.001$ & $\mathrm{p}<0.001$ \\
Clássico & $109.9( \pm 2.37)$ & $\mathrm{NS}$ & $\mathrm{p}<0.05$ & $\mathrm{NS}$ & $\mathrm{NS}$ \\
\hline
\end{tabular}

NS = Non-significant. 
elasticity, thereby producing a less rigid material at room temperature. The plastifying agent also penetrates into the molecules and increases the intermolecular spaces, which partially neutralize the secondary bonds or intermolecular forces and usually hamper the sliding movement of resin molecules when the material is submitted to tension forces ${ }^{15-17}$.

Low module of elasticity produces a larger resilience module, consequently, higher is the energy-absorbing capacity and higher will be the deflexion force released on the material ${ }^{11,12}$. This result is in agreement of our study, which showed that the concentration of added elastomer was directly proportional to the resistance to impact. The addition of elastomer to the material increases the ability of absorb energy and overcome the possibility of resin fracture, which can result in prosthetic device less susceptible to mechanical failure.

Regarding the resistance to fracture, it was verified that, among the commercial materials, Lucitone 550 had the best performance. This result can be explained by the presence of ethylene glycol dimethacrylate (EGDMA) on its composition ${ }^{17}$. EGDMA is a crosslinking agent that connects the polymer chains and produces a more rigid material. However, the elastomer addition wasn't efficient enough to improve this property in the experimental materials ${ }^{17}$.

Concerning the fracture resistance test, the ground material with the lowest amount of added elastomer (10\% EDA) had lower resistance values than Lucitone 550. The same fact was observed for all the materials processed by injection technique. Due to the compactness and higher amount of monomer available in the mixture, the ground materials might have larger intermolecular distances, which could justify their best resistance to impact. Similar results were reported by other authors ${ }^{5,10,16}$. Moreover, it should be consider that traditional technology of mixing powder to liquid, condensing and curing the material is very simple and should not be totally replaced.

Finally, the outcomes of the present study agree with Jagger et al. ${ }^{6}$, which reported that the addition of rubber to PMMA as a reinforcement method is an successful alternative to the conventional PMMA denture base resin. However, complementary studies that analyses the conversion degree and esthetic properties are still necessary for complete understanding these promising materials.

\section{Conclusions}

- Overall, the ground materials had higher resistance to impact and fracture when compared to those that were injected. The only exception was the EDA material, which had similar resistance to fracture, regardless of the processing technique.

- The concentration of added elastomer was directly proportional to the resistance to impact. Considering the resistance to fracture, the same performance occurred only to the ground material. The injected experimental materials, regardless of the concentration of elastomer, did not interfere in fracture resistance.

- Above $40 \%$ of elastomer addition, the resistance to impact of experimental materials was higher than the commercials. The same performance was obtained for ground materials in the resistance to fracture tests.

\section{References}

1. Jagger DC, Jagger RG, Allen SM and Harrison A. An investigation into the transverse and impact strength of "high strength" denture base acrylic resins. Journal of Oral Rehabilitation. 2002; 29(3):263-267.

2. Beyli MS and von Fraunhofer JA. An analysis of causes of fracture of acrylic resin dentures. The Journal of Prosthetic Dentistry. 1981; 46(3):238-241.

3. Hargreaves AS. The prevalence of fractured dentures. A survey. British Dental Journal. 1969; 126(10):451-455.

4. Lai CP, Tsai MH, Chen M, Chang HS and Tay HH. Morphology and properties of denture acrylic resins cured by microwave energy and conventional water bath. Dental Materials. 2004; 20(2):133-141.

5. Zappini G, Kammann A and Wachter W. Comparison of fracture tests of denture base materials. The Journal of Prosthetic Dentistry. 2003; 90(6):578-585.

6. Jagger DC, Harrison A and Jandt KD. The reinforcement of dentures. Journal of Oral Rehabilitation. 1999; 26(3):185-194.

7. Memon MS, Yunus N and Razak AA. Some mechanical properties of a highly cross-linked, microwave-polymerized, injection-molded denture base polymer. The International Journal of Prosthodontics. 2001; 14(3):214-218.

8. Phoenix RD, Mansueto MA, Ackerman NA and Jones RE. Evaluation of mechanical and thermal properties of commonly used denture base resins. Journal of Prosthodontics. 2004; 13(1):17-27.

9. Polyzois GL, Tarantili PA, Frangou MJ and Andreopoulos AG. Fracture force, deflection at fracture, and toughness of repaired denture resin subjected to microwave polymerization or reinforced with wire or glass fiber. The Journal of Prosthetic Dentistry. 2001; 86(6):613-619.

10. Stafford GD, Huggett R and Causton BE. Fracture toughness of denture base acrylics. Journal of Biomedical Materials Research. 1980; 14(4):359-371.

11. Rodford R. The development of high impact strength denture-base materials. Journal of Dentistry. 1986; 14(5):214-217.

12. Rodford RA. Further development and evaluation of high impact strength denture base materials. Journal of Dentistry. 1990; 18(3):151-157.

13. Neihart TR, Li SH and Flinton RJ. Measuring fracture toughness of high-impact poly (methyl methacrylate) with the short rod method. The Journal of Prosthetic Dentistry. 1988; 60(2):249-253.

14. Harrison A, Huggett R and Jagger RC. The effect of a cross-linking agent on the abrasion resistance and impact strength of an acrylic resin denture base material. Journal of Dentistry. 1978; 6(4):299-304.

15. Hill RG. The crosslinking agent ethylene glycol dimethacrylate content of the currently available acrylic denture base resins. Journal of Dental Research. 1981; 60(3):725-726.

16. Price CA. The effect of cross-linking agents on the impact resistance of a linear poly (methyl methacrylate) denture-base polymer. Journal of Dental Research. 1986; 65(7):987-992.

17. Faot F, Costa MA, Del Bel Cury AA and Rodrigues Garcia RC. Impact strength and fracture morphology of denture acrylic resins. The Journal of Prosthetic Dentistry. 2006; 96(5):367-373. 